\title{
MAO TSE-TUNG EN BOGOTÁ. EL PRAGMATISMO DE LAS FARC Y SU \\ PARALELO EN CHINA
}

\section{MAO TSE-TUNG EN BOGOTA. EL PRAGMATISM LAS Y SU PARALLEL FARC EN CHINA}

\section{Gabriel A. Méndez ${ }^{1}$}

Resumen: Este artículo tiene como objetivo analizar los cambios ocurridos en el paradigma del Estado colombiano hacia adelante el Proceso de paz propuesto por la guerrilla en la Reserva Campesina (ZRC) Áreas baño territorio nacional el, estableciendo un paralelo la política "y de la ONU, los sistemas "implementado por sus líderes demócratas de China Despues de la muerte de Mao.

Palabras clave: ESTADO. LAS GUERRILLAS. PROCESO DE PAZ. CHINA.

Abstract: This article aims to analyze the changes in the paradigm of the Colombian State forward the peace process proposed by the guerrillas in the Rural Reserve (ZRC) national territory bathroom areas, setting up a parallel political "and UN the systems "implemented by his Democratic leaders of China After Mao's death.

Keywords: STATE. THE GUERRILLAS. PEACE PROCESS. CHINA

\section{INTRODUÇÃO}

Los analistas del actual proceso de paz en Colombia han pasado por alto el curioso paralelo entre la propuesta de la insurgencia guerrillera de establecer alrededor de 50 Zonas de Reserva Campesina (ZRC) en el territorio nacional y la 
política de "un país, dos sistemas" implementada por la dirigencia China después de la muerte de Mao.

El camino de la paz entre China y Estados Unidos se obtuvo por la competencia pacífica entre los dos sistemas. Poseía un tinte novedoso y poco estudiado por los filósofos políticos occidentales: la conexión marxismo-pragmatismo en lugar de la tradicional disputa entre marxismo y liberalismo. Al parecer, al Sur Global en general y a Colombia en particular, también les ha llegado el momento de reconocer que "poco importa que el gato sea blanco o negro, con tal que cace ratones" (Deng Xiaoping). A comienzo de los años 80, la política de "un país, dos sistemas" significaba que China conservaría el sistema comunista; mientras que en Hong Kong y los territorios de ultramar, Taiwán, Macao y Singapur, continuarían con el sistema capitalista comandado por Estados Unidos.

En palabras de Deng Xiaoping, (1984) "un país, dos sistemas" quería decir que

"[...] El mundo enfrenta la elección entre métodos pacíficos y no pacíficos de resolución de conflictos. De una forma u otra deben resolverse. Nuevos problemas deben ser resueltos por nuevos mecanismos. La exitosa resolución de la cuestión de Hong Kong puede promover elementos útiles para la solución de conflictos internacionales. ¿Ha perseguido algún gobierno en la historia mundial, una política tan generosa como la China? ¿Hay algún registro, en la historia del capitalismo de que algún país occidental haya hecho algo similar?".

A continuación, examino los antecedentes geopolíticos de la estrategia China y luego comparo sus características principales con el caso colombiano.

\section{EL CISMA COMUNISTA:}

En la prensa occidental se tiende a decir que la apertura y las reformas en la China comunista tuvieron que esperar a la muerte de Mao para ser implementadas por una nueva dirigencia más liberal o disidente.

Sin embargo, ya en 1956 durante el V Congreso del Partido Comunista de China PCCh-, Mao se había pronunciado sobre una eventual colaboración de los 
comunistas chinos con los capitalistas nacionales. Ya en ese entonces, como posteriormente recordará un dirigente eurocomunista invitado al mencionado congreso (Carrillo, 2006) Mao aconsejaba "ofrecer diez mil años de vida a la burguesía".

Así, mucho antes de la muerte de Mao, ya estaba presente en la cúpula dirigente china la semilla de una posible alianza entre el Partido Comunista y los capitalistas chinos expatriados. Sin embargo, tomaría su tiempo y no pocos riesgos para que se desarrollara todo el proceso.

Quizá el momento más dramático de ese desarrollo se presentó cuando la tensión entre China y Rusia llegó al enfrentamiento militar en la frontera siberiana en el río Ussuri, en 1969. Según el posterior relato de Kissinger (2011) las poblaciones de los dos países daban por casi inevitable un enfrentamiento nuclear que llevaría a la construcción en China de una red de refugios en las principales ciudades. Incluso en el Estado Mayor soviético se había llegado a considerar la opción de un ataque preventivo sobre la provincia de Singkiang, donde China preparaba su armamento nuclear. Los chinos descartaban cualquier amenaza de ese tipo por parte de los norteamericanos, pero la consideraban muy probable de Moscú.

¿Qué proceso motivó la ruptura chino-soviética hasta semejante punto de inflexión? Según Wallerstein (2004), todo comenzó en los años 50 con un debate en torno a la cuestión teórica de la transición al comunismo. Los soviéticos argumentaban que cada país socialista podía llevar a cabo de forma independiente esa transición, mientras que los chinos planteaban que todos los países socialistas la llevarían a cabo simultáneamente.

Obsérvese que el enfoque del PCCh sostenía que el comunismo (sea lo que sea) no era algo propio de los Estados-nacionales como lo concebían en Occidente, "sino del conjunto de la economía-mundo" (Wallerstein, 2004). Una de las consecuencias más importantes de ese debate fue el papel reservado para la 
lucha de clases en todo el proceso de transición. Para Mao, la lucha de clases no terminaba con la instauración del socialismo en los estados nacionales. Y esta aseveración se constituyó en la clave del proceso que daría lugar a la Revolución Cultural. Con ese argumento, Mao invitaría a los Guardias Rojos, una década más tarde, a "abrir fuego contra el cuartel general" de Pekín. Por el contrario, los soviéticos argüían —cínicamente- que la URSS y sus satélites del Pacto de Varsovia constituían una pacífica y armoniosa unión de repúblicas y nacionalidades.

Son notables las diferencias entre ambas posturas. Mientras Mao defendía una exacerbación de la lucha de clases en todos los ámbitos de la confrontación con el capitalismo, al mismo tiempo no desechaba alianzas con el sistema rival como parte de una estrategia a más largo plazo del movimiento comunista internacional. Por el contrario, la nueva dirigencia soviética quería superar y denunciar la brutalidad stalinista y alcanzar a corto plazo algún tipo de coexistencia con el capitalismo.

Hoy la historia de la disputa chino-soviética por la dirección de la revolución mundial parece un debate esotérico. No obstante, ese debate estuvo a punto de desencadenar, durante la guerra fría, una conflagración nuclear en Asia y Europa.

El hecho es que China, durante esos años y debido a la amplia intervención del Ejército Popular de Liberación (EPL) en la guerra de Corea contra el ejército de Estados Unidos, no tenía ni siquiera reconocimiento diplomático occidental. Su puesto en el sistema internacional lo estaba usurpando el régimen de Taiwán. Por tanto, a los ojos de los dirigentes chinos, la revolución no estaría terminada hasta que no se lograra la unificación plena del territorio, lo cual implicaba extender la guerra contra el capitalismo desde Corea hasta Taiwán, Hong Kong, etc. Sin embargo, para que China estuviera en condiciones de continuar la guerra contra Estados Unidos y sus aliados, después del alto al fuego pactado en Corea, 
necesitaba la ayuda técnico-militar de Rusia. Pero los rusos condicionaban toda su ayuda a la sumisión de China a las necesidades soviéticas.

La verdad es que las hostilidades entre China y Rusia se remontaban hasta el origen del PCCh. Desde los años 20, Mao se había opuesto a la injerencia soviética sobre China a la que llegaría a calificar más tarde de imperialista. Para él estaba claro que el PCCh no podía copiar y adaptar las estrategias de sus "camaradas" occidentales. Los soviéticos, por el contrario, no solo habían apoyado a los rivales de Mao, en particular al Kuomintang que ahora gobernaba con puño de hierro en Taiwán, sino que venían de una tradición revolucionaria que había asesinado, no solo a sus antiguos camaradas bolcheviques, sino a millones de campesinos al considerarlos una clase social contra-revolucionaria.

A mediados de los años 60, las diferencias entre China y Rusia alcanzaron el nivel máximo de tensión. Al romper relaciones con su único aliado, China quedaba totalmente aislada del mundo exterior. Previendo una guerra, China responde con su primera prueba nuclear en 1964 y con el lanzamiento de su primer cohete balístico, en 1966. Sin embargo, la guerra no se desató. No obstante, el costo de su preparación era inmenso para la exhausta y completamente bloqueada economía china.

Comienza a sentirse dentro del PCCh la oposición a las políticas de Mao. Entonces, para defender su posición éste contraataca lanzando la Revolución Cultural. Luego, en medio del caos desatado por los guardias rojos algunos dirigentes chinos como Lin Biao, "número dos" del régimen, intentan hacerse con el poder y realinear China con la URSS. Finalmente, los planes soviéticos de someter a China por medio de un golpe de estado fracasan. Pero curiosamente, por esas fechas también fracasa la intervención estadounidense en Vietnam. Así pues, casi simultáneamente quedan en evidencia los límites de las nuevas potencias occidentales en su intento de volver a colonizar Asia Oriental. 
Volviendo al relato de Kissinger, en 1969 Mao convoca a un grupo de cuatro mariscales del EPL, -Chen Yi, Nie Rongzhen, Xu Xianggian y Ye Jianying- que habían sido perseguidos durante la Revolución Cultural. Su misión era elaborar un informe sobre las opciones estratégicas para China ante los desafíos y oportunidades surgidas del doble fracaso soviético y estadounidense en Asia Oriental.

El informe de esta Comisión Militar inspiró el giro radical de la política interior y exterior China y el comienzo de las reformas y la apertura. En sus conclusiones los mariscales señalaron al imperialismo soviético como la principal amenaza a la seguridad de China. Recomendaron seguir la estrategia de Sun Tzu de "poder vencer al enemigo sin llegar a la batalla". Al poco tiempo, en 1972, Mao y Nixon se reúnen y firman el "comunicado de Shanghai" dando así inicio a la política triangular que facilitó el retorno de China al escenario internacional dominado por occidente.

Al poco tiempo el primer ministro Zhou Enlai, bajo la conducción de otra famosa víctima de la Revolución Cultural, el rehabilitado primer viceprimer ministro, Deng Xiaoping, lanza el programa de las "cuatro modernizaciones" (de la agricultura, la industria, el desarrollo científico- tecnológico y la defensa nacional).

Tras la muerte de Mao y de Zhou Enlai (1976-1977), la facción que apoya a Deng Xiaoping se hace con el poder -gracias al apoyo del EPL-y en un par de años logran expulsar de la cúpula del partido y luego poner bajo arresto a los altos cargos de la facción rival conocida como la "Banda de los Cuatro" por los crímenes y excesos cometidos durante la Revolución Cultural.

Deng Xiaoping consolida la paz con Estados Unidos y hace la siguiente gran jugada estratégica: la alianza con los capitalistas expatriados de la que hablara 
Mao -sibilinamente- durante el $\vee$ Congreso del $\mathrm{PCCh}^{2}$. En pocas palabras, la política de "un país, dos sistemas" fue la solución al enigma de cómo realizar las cuatro modernizaciones recomendadas por Zhu Enlai, poco antes de morir.

Se podría argumentar en clave gramsciana, que Deng Xiaoping y la nueva dirigencia decidieron pasar, tras la muerte de Mao, de una estrategia de "guerra de movimientos" con EE.UU (o la URSS), a otra de "guerra de posiciones" o competencia pacífica.

El "transformismo" de las reforma chinas comenzó por la principal: la introducción en 1978-1983 del Sistema de Responsabilidad Familiar (SRF) 3: devolvía a los hogares del campo el control sobre los excedentes agrícolas hasta entonces en manos de las comunas. Al mismo tiempo, se permitió una liberación de los precios agrícolas en origen lo que incentivó la producción en el campo. La productividad agrícola y los ingresos de los hogares campesinos aumentaron notablemente.

Ahora bien, no se debe olvidar que, a diferencia de los países capitalistas, en aquella época el Estado era propietario de la tierra. El gobierno, a través de las comunas, controlaba la explotación y uso de las tierras. Con el SRF dicho control pasaba a las familias campesinas a través de contratos de arrendamiento por 50100 años. Pero la propiedad de la tierra seguía siendo del Estado. La siguiente fase fue permitir a los campesinos de las comunas, donde se ensayaba el SRF, realizar negocios fuera de sus aldeas con el fin de buscar salidas para sus productos.

Fue la primera vez en toda una generación que a los agricultores chinos se les dio el derecho a realizar negocios fuera de sus lugares de residencia.

\footnotetext{
${ }^{2}$ Se pueden hallar antecedentes del pragmatismo de la dirigencia china en la NEP de Lenin, que en los años 20 y sorprendiendo a todos recomendó para una joven Unión Soviética. Véase, Slavoj Zizek (2009).

${ }^{3}$ Aquí sigo la exposición de Giovanni Arrighi de su obra Adam Smith en Pekín.
} 
A continuación, en 1984, se flexibilizaron aún más las regulaciones que controlaban la movilidad espacial de los campesinos para permitirles trabajar en ciudades cercanas a sus aldeas de residencia en las Empresas de Pueblo y Ciudad (EPC) de propiedad colectiva. Su explosivo crecimiento, era un resultado inesperado del exitoso SRF. En efecto, las EPC eran el medio para la reasignación de los excedentes agrícolas producidos por los incrementos de la productividad rural desencadenados por el SRF.

El resultado fue un crecimiento impresionante de la mano de obra rural dedicada a actividades no agrícolas, que pasó de 28 millones de campesinos en 1978 a 176 millones de 2003, la mayoría de ellos empleados en las EPC.

La propiedad de las EPC estaba asignada a todos los habitantes del correspondiente pueblo o ciudad aunque los gobiernos locales, controlados por el PCCh, tenían autoridad para nombrar y despedir a los administradores o delegar esa autoridad en una agencia gubernamental especializada. $Y$ dado que los beneficios que producían las EPC debían invertirse obligatoriamente en las propias empresas y en obras sociales locales, en China se estaba gestando una gigantesca acumulación de capital sin desposesión de los trabajadores ${ }^{4}$.

La siguiente fase de la modernización de la economía china fue la internacionalización de las EPC a través del contacto entre las autoridades locales del PCCh, que controlaban su gestión, con los capitalistas de la diáspora china residentes en Hong Kong, Singapur y Taiwán, quienes a su vez pusieron la mano de obra de China al servicio del capitalismo global, por medio de la creación de colosales Zonas de Procesamiento de Exportaciones (ZPE). En síntesis: Modernización $=\mathrm{SRF}+\mathrm{EPC}+\mathrm{ZPE} \mathrm{Y}$ son estas reformas "transformistas" (en sentido gramsciano) las que hacen que Estados Unidos se vea obligado a no

\footnotetext{
${ }^{4}$ Sin embargo, a la acumulación sin desposesión de los años 80 le siguió una salvaje "acumulación originaria" capitalista desde los años 90 hasta hoy. Según Naomi Klein (2008), el punto de inflexión de este shock hacia el capitalismo se halla en la matanza de la Plaza de Tian'anmen.
} 
entorpecer el ascenso de China a la jerarquía mundial, en un intento por mantener su hegemonía cuestionada desde la guerra del Vietnam.

\section{3. ¿PRIMERO COMO TRAGEDIA, DESPUÉS COMO COMEDIA? EL PRAGMATISMO DE LAS FARC}

Como se ha visto, durante la guerra fría las contradicciones internas del movimiento comunista internacional por el control de la revolución mundial llevaron al mundo hasta el borde de una guerra nuclear. Dichas contradicciones también fueron vividas de manera trágica en Colombia (Valencia, 2008).

Aquí y durante ese oscuro periodo de la "guerra fría", no sólo la guerra sucia contrainsurgente desplegada por la CIA (y sus agentes locales desde el Estado) ${ }^{5}$, sino también las persecuciones y fusilamientos entre "compañeros", cooperaron absurda y trágicamente para exterminar las fuerzas insurgentes y de paso desmoralizar o radicalizar a muchos activistas de todos los partidos y movimientos de la izquierda democrática.

La llamada "combinación de todas las formas de lucha" por parte de las principales fuerzas políticas (de izquierda y derecha) facilitaron la perpetuación de múltiples crímenes de lesa humanidad. Y si a las razones geopolíticas que explican esos crímenes se le suman las aportadas por la dimensión geo-narcótica del conflicto, es decir, las inhumanas consecuencias de la explotación capitalista de la demanda mundial de drogas ilegales, se puede intuir la compleja matriz del atroz conflicto armado que vive Colombia.

Sin embargo, ahora que el gobierno y la insurgencia colombiana buscan una vez más en La Habana (Cuba) una salida negociada al complejo conflicto armado, vale la pena señalar el curioso paralelo que, a mi modo de ver, existe entre la

\footnotetext{
${ }^{5}$ Archivo de Seguridad Nacional de Estados Unidos en http://www.gwu.edu/ nsarchiv/
} 
sorprendente propuesta de las FARC de establecer unas Zonas de Reserva Campesina (ZRC), así como otras zonas especiales en los territorios indígenas y de afrodescendientes, como núcleo de su estrategia política de mediano y largo plazo y la mencionada política de "Un país, dos sistemas" planteada en las negociaciones de paz entre el capitalismo liderado por EE.UU. y la antigua dirigencia comunista de China.

Para firmar la paz con el Estado colombiano, las FARC piden unas ZRC de nueve millones de hectáreas, unas Zonas de Producción Campesina de Alimentos de siete millones de hectáreas, a las que hay que agregar los cerca de 30 millones de hectáreas de los resguardos indígenas y los cuatro millones de hectáreas de los territorios de afrodescendientes, con lo cual tenemos alrededor de 50 millones de hectáreas que harían parte de jurisdicciones especiales donde el capitalismo no podría campar a sus anchas. Se trata del 40 por ciento del territorio nacional donde habita alrededor del 15 por ciento de la población del país.

Para esas jurisdicciones las FARC proponen, como en su momento Deng Xiaoping ofrecía a los capitalistas chinos de Hong Kong, Macao, y Taiwán, una autonomía política, económica y administrativa, lo cual significa para el caso colombiano, que el poder central del Estado tendría la soberanía compartida sobre cerca de la mitad del territorio, quedando así el país ad portas de constituirse en una república territorialmente reintegrada bajo alguna modalidad de federalismo asimétrico plurinacional ${ }^{6}$. Como lo es hoy mutatis mutandis la Gran China, un territorio que comprende, además de China continental, a Hong Kong, Taiwán, Macao, y las redes de capitalistas chinos expatriados en Singapur, Malasia, etc., más conocidas como "la diáspora china".

La iniciativa de las FARC de crear 59 zonas de reserva campesina (ZRC) con una extensión de 9,5 millones de hectáreas tiene implicaciones políticas y económicas que pueden llegar a ser positivas tanto para el pueblo impostor como para el

\footnotetext{
${ }^{6}$ En el contexto suramericano Bolivia y Ecuador están a la vanguardia de dicho modelos.
} 
pueblo oculto (Sanín, 2013 \& Agamben, 1998) colombiano. Para empezar, es pertinente señalar que 9,5 millones de hectáreas no es un área despreciable: prácticamente es el doble de la totalidad del área agrícola del país.

Concretamente las FARC plantean la: "Constitucionalización de la figura del territorio campesino, en cabeza de las comunidades campesinas y de sus organizaciones, la cual representará una de las formas de organización territorial del Estado colombiano en los mismos términos que para las comunidades indígenas y afrodescendientes. En tal sentido, los territorios campesinos serán inembargables e imprescriptibles" (Botero, 2013).

En la negociación las FARC proponen que los "los territorios campesinos gozarán de autonomía política, administrativa, económica, social, ambiental y cultural, y en la administración de justicia a través de los mecanismos de la justicia comunitaria. La autonomía se comprende en términos de la capacidad de autogobierno, autogestión y autodeterminación, enmarcada dentro del ordenamiento constitucional que resulte del nuevo contrato social pactado en la Asamblea Nacional Constituyente" (Botero, 2013). Así pues, los vientos de la nueva izquierda latinoamericana comienzas a soplar más allá de los países del ALBA.

De las propuestas de las FARC respecto a las ZRC se deducen varias conclusiones: la primera es que la insurgencia concibe la economía en general, y la economía agraria en particular, como una dimensión totalmente integrada a la autonomía política, administrativa y no como si "la economía" y "la política" fueran dos esferas separadas ${ }^{7}$.

La segunda, que en un país capitalista y postcolonial que alberga y mantiene notables e irreconciliables desigualdades entre el pueblo oculto y el pueblo impostor de la democracia liberal, las ZRC no serían necesariamente una calamidad. Dos sistemas socioeconómicos, el capitalismo neoliberal del Estado

\footnotetext{
${ }^{7}$ En esto sigo libremente las ideas de Ellen M. Wood (2004)
} 
central y la nueva izquierda latinoamericana de las ZRC podrían coexistir "en paz" y enseñar erga omnes sus diversos logros y desventajas. Una vez más, como en la China postmaoista ${ }^{8}$.

Es fundamental blindar la estructura jurídica-constitucional planteada por las FARC para las ZRC en el campo económico. En primer lugar, las ZRC se convertirían en territorios campesinos inembargables e imprescriptibles, con lo cual los ecosistemas y sus pobladores no podrían seguir siendo considerados como activos; es decir, como mercancías embargables con lo cual la propiedad colectiva quedaría blindada contra la especulación del sistema crediticio capitalista. No obstante, las ZRC al quedar convertidos en territorios libres de la financiarización y no ser sujetos del sistema financiero capitalista, ¿de dónde obtendrán recursos para la inversión real?

Para que los campesinos y los pueblos aborígenes de las ZRC puedan pervivir y además ser productores eficientes de alimentos y eficaces protectores del agua y la biodiversidad tropical, las FARC y el Estado colombiano tendrán que negociar inexorablemente con los gobiernos estadounidenses y europeos la sustitución integral de los narco-cultivos a cambio de un porcentaje adecuado de los impuestos que ellos destinan a financiar la fallida "guerra contra las drogas". De esta forma se subsidiaría indefinidamente ${ }^{9}$ con una fracción de los recursos fiscales del Norte la inversión para la protección y desarrollo sustentable de las ZRC del Sur. La paz en Colombia tiene así el potencial de cambiar la dimensión geo-narcótica de la política mundial. Adicionalmente, el Norte financiaría la conservación ecológica de las ZRC como sumideros de gases de efecto

\footnotetext{
${ }^{8}$ No obstante, la propuesta de las FARC también presenta similitudes con el modelo de las Zonas de Extracción en Brasil. Dicho modelo es consecuencia directa de las luchas del movimiento campesino amazónico (Chico Mendes). Desde hace una década el gobierno brasileño de centro izquierda ha promovido el modelo de Zonas de Extracción, que blinda decenas de millones de hectáreas de la selva tropical y a su pueblo oculto de los excesos del capitalismo agrario.

${ }^{9}$ Siempre y cuando las agencias de la ONU, el CICR, etc, verifiquen in situ y permanentemente la efectiva sustitución de los narco-cultivos en las ZRC.
} 
invernadero en forma de proyectos agro-forestales, ecoturismo, energías alternativas, biotecnologías.

Por tanto, al igual que en las negociaciones entre la dirigencia del PCCh y sus capitalistas nacionales de entonces, las FARC y el gobierno colombiano tienen que ser plenamente conscientes de que el acuerdo de paz necesita del fiat de la potencia hegemónica capitalista para que se pueda hacer realidad. Sin la participación de los Estados Unidos, la UE y los emergentes BRIChs, la paz no sería más que un deseo piadoso.

Por otra parte, ¿qué hacer con el tema de la justicia penal? ¿Cómo reparar a las víctimas civiles del accionar militar de las FARC y de la contrainsurgencia? Una opción es que los insurgentes y los agentes del Estado procesados y condenados en juicios supervisados por la Corte Penal Internacional -CPI- podrían cumplir penas alternativas en las ZRC, monitoreados por Amnistía Internacional.

\section{4. ¿CABE ALGUNA ESPERANZA DE QUE SE PUEDA REALIZAR?}

Si hace 40 años el presidente Mao y un criminal de guerra de la talla mundial como Henry Kissinger (Hitchens, 2005), lograron negociar la paz entre China y el capitalismo global, ¿por qué no podrían hacer algo similar los líderes de la insurgencia colombiana y del capitalismo nacional? Si ya fue posible una exitosa negociación entre la izquierda radical de China y la extrema derecha de Estados Unidos, ¿por qué no puede repetirse ahora esa comedia y evitar la continuación de esta tragedia colombiana?

Los temores de la derecha colombiana son infundados. Siguiendo con el paralelo chino, desde hace años quedó demostrado que firmada la paz entre las dos partes claramente es el capitalismo el que con el tiempo ha conquistado, para bien y para mal, toda la China. Firmada la paz, la izquierda radical debe demostrar que es capaz de resistir la corrupción inherente al capitalismo y administrar justa y 
eficientemente las ZRC si no quiere que con el tiempo dichos territorios y pueblos opten por la resistencia o la rebelión.

¿Podrá el pragmatismo de las FARC lograr un objetivo que nunca pudieron alcanzar los revolucionarios en otras latitudes?

\section{BIBLIOGRAFÍA}

Agamben, G.: Homo Sacer: Sovereign power and Bare Life, Stanford University Press, 1998.

Arrighi, G.: Adam Smith en Pekín, Madrid, Akal, 2007.

Botero, M.: “¿Incubadoras de miseria?” En: El Espectador, Bogotá, marzo 23 de 2013. http://www.elespectador.com/noticias/paz/articulo-412162-incubadoras-demiseria.

Carrillo, S.: Memorias, Barcelona, Planeta, 2006.

Hitchens, C.: The trial of Henry Kissinger, London, Verso, 2001.

Kissinger, H.: China, Barcelona, Debate, 2012.

Klein, N.: La doctrina del shock. El auge del capitalismo del desastre, Buenos Aires, Paidós, 2008.

Sanín, R.: "Cinco tesis desde el pueblo oculto", En: Constitucionalismo popular en Latinoamérica, Alterio y Ortega (Comp.), México, Porrúa, 2012.

Valencia, L.: Mis años de guerra, Bogotá, Ed. Norma, 2008. 
Wallerstein, I.: Capitalismo histórico y movimientos antisistema, Madrid, Akal, 2004.

Wood, M. E.: El imperio del capital, Madrid, Viejo Topo, 2004.

Xiaoping, D.: "Un país, dos sistemas", En: Marxists Internet Archive. www.marxists.org/deng/1984/junio22/htm

Zizek, S.: "Como empezar por el principio" en: New Left Review, No. 57, pp. 43-55, Madrid, Akal, Mayo/Junio, 2009. 